\title{
Shellfish Mix Antigen IgG Antibody Measurement
}

National Cancer Institute

\section{Source}

National Cancer Institute. Shellfish Mix Antigen Ig G Antibody Measurement. NCI

Thesaurus. Code C130121.

A measurement of the shellfish mix antigen Ig G antibody in a biological specimen. 